\title{
Different Stages of B Cell Differentiation in Non-T Acute Lymphoblastic Leukemia
}

\author{
R. Foa, N. Migone, M. Saitta, M. T. Fierro, \\ M. C. Giubellino, P. Lusso, L. Cordero di Montezemolo, \\ R. Miniero, and F. Lauria \\ Clinica Medica A, University of Torino; Istituto di Genetica \\ Medica dell' Università e Centro CNR, Immunogenetica ed \\ Istocompatibilità, Torino; Ospedale Infantile Regina Margherita, \\ Torino; Istituti Universitari di Pediatria, Torino, Italy; Istituto di \\ Ematologia "L. \& A. Seragnoli", University of Bologna, Italy
}

bstract. Immunoglobulin heavy chain gene rearrangement was evaluated in 19 cases of acute lymphoblastic leukemia (ALL) and correlated with the immunological phenotypic expression on primary or phorbol diester (12-O-tetradecanoylphorbol-13-acetate [TPA])-induced cells. One case of common ALL (cALL), one case of T-ALL, and one undifferentiated acute leukemia that responded to anti-myeloid drugs after unsuccessful anti-lymphoid induction therapy, had germ line heavy chain genes. Rearranged immunoglobulin genes were instead found in 15 of the $16 \mathrm{cALL}$ cases studied and in a case of non- $T$, non-B, non-common ("null") ALL, which suggested the B cell origin of the neoplastic cells.

All cases bearing a heavy chain gene rearrangement were HLA-DR positive. However, the unique CALL case with a germ line configuration was also HLA-DR positive, which confirmed that both the cALL antigen and HLA-DR antigen were not per se expression of $B$ cell commitment. On the other hand, a complete search for B cell-related markers (BA-1 and B1 monoclonal antibodies, as well as cytoplasmic immunoglobulins [CyIg]) in the cALL cases showed that at least one B cell marker could be detected either on primary or on TPA-induced cells in all cases in which a gene rearrangement had occurred. Incubation with TPA allowed the detection of one B cell marker in a case in which the primary cells were negative, and increased the expression

Address correspondence to Dr. Foa, Clinica A, Via Genova 3, 10126 Torino.

Received for publication 18 January 1984 and in revised form 24 May 1984.

J. Clin. Invest.

(c) The American Society for Clinical Investigation, Inc. 0021-9738/84/11/1756/08 \$1.00

Volume 74, November 1984, 1756-1763 of B cell markers in all but one of the cALLs tested. The only cALL case that was not rearranged expressed no B cell markers either on primary or on TPA-induced cells. The non-T, non-B, non-common ("null") case that was rearranged also showed no phenotypic evidence of $B$ cell markers on primary and induced cells.

These findings indicate that: $(a)$ practically all cases of cALL appear to be of B cell origin as shown by gene rearrangement analysis; (b) DNA studies are relevant for a more precise characterization of individual cases of undifferentiated acute leukemia; (c) a complete survey for B cell markers may establish the B cell origin of the cALL blasts, as long as the analysis on primary cells is complemented by differentiation induction assessment; and $(d)$ most cases of non-T ALL appear to be characterized by the expansion of neoplastic cells "frozen" at different levels along the B cell differentiation pathway; the first detectable marker being heavy chain gene rearrangement, followed by BA-1, B1, and CyIg expression.

\section{Introduction}

On the basis of conventional immunological markers, $\sim 70-80 \%$ of the cases of acute lymphoblastic leukemia (ALL) ${ }^{1}$ cannot be assigned to either the $T$ or the $B$ cell lineage. The common ALL(cALL)-associated antigen (1), which reacts with the majority of non-T, non-B ALLs, does not define the origin of these cells. The first suggestion that a proportion of non- $T$ ALL was in fact B cell committed was based on the presence of cytoplasmic immunoglobulin (CyIg) $\mu$ chains in $\sim 25 \%$ of the patients (2). Further support for this hypothesis is obtained

1. Abbreviations used in this paper: $\mathrm{ALL}$, acute lymphoblastic leukemia; $\mathrm{AL}$, acute leukemia(s); cALL, common ALL(s); CyIg, cytoplasmic immunoglobulin; kb, kilobase(s); MoAb, monoclonal antibody(ies); SSPE; salt-sodium phosphate-EDTA solution; TPA, 12-O-tetradecanoylphorobol-13-acetate; TdT, terminal deoxynucleotidyl transferase; $\mathrm{JH}$, heavy chain joining region. 
by recently developed monoclonal antibodies (MoAbs) which react primarily with malignant $B$ cells (3). In particular, one of these MoAbs, named BA-1, recognizes most cases of non$T$, non-B ALL (4). Another MoAb, termed B1, has been reported to react with antigens present on $\sim 50 \%$ of non-T ALL (5). Furthermore, in a small number of patients, the leukemic cells could be induced to express B cell related antigens after incubation with differentiation agents $(6,7)$.

It has recently been shown that before immunoglobulin (Ig) expression a gene rearrangement must occur at the DNA level (8-10) (Fig. 1). This approach has proved valuable for a more precise definition of the cellular origin of $\operatorname{ALL}(12,13)$ and of chronic granulocytic leukemia in lymphoid blast crisis $(14,15)$.

In the present study, we have found heavy chain gene rearrangement in all but one case of CALL and in one non-T, non-B, non-common ("null") ALL. One T ALL case and one case expressing an undifferentiated phenotype, which responded to anti-myeloid cytotoxic drugs after unsuccessful anti-ALL induction therapy, retained germ line Ig genes.

After assessment for different B cell markers either on primary cells or after differentiation induction with the tumor promoter 12-O-tetradecanoylphorbol-13-acetate (TPA), all cALL cases except one expressed at least one or more markers of the B cell lineage. Based on these findings, it is conceivable that practically all cases of ALL belong either to the $T$ or to the B cell line of differentiation, and that non-T ALLs represent the malignant expansion of neoplastic cells blocked at different stages along the $B$ cell differentiation pathway.

\section{Methods}

Samples. Analyses were carried out using heparinized sterile bone marrow specimens or, less frequently, peripheral blood samples from 19 unselected ALL patients in whom the differential count showed a complete invasion by leukemic cells. In all cases, test cells were recovered from the interface after a "Lymphoprep" (Nyegaard A/S \& Co., Oslo, Norway) gradient separation.

Markers. All samples were examined for rosette formation with sheep erythrocytes (E-rosettes) and for the presence of surface Ig. CyIgs were evaluated on cytocentrifuge preparations using a rhodamine conjugated rabbit Ig anti-human IgM (Dako Immunoglobulins Ltd., Copenhagen, Holland). Terminal deoxynucleotidyl transferase (TdT) analysis was carried out on cytocentrifuge preparations, which were fixed in cold methanol for $30 \mathrm{~min}$ and stained with a rabbit antihuman TdT and (as second layer) with a fluorescein conjugated goat anti-rabbit. Both reagents were purchased from Bethesda Research Laboratories, Inc., Gaithersburg, MD.

Monoclonal antibodies. Several of the following MoAbs were employed in various combination, according to the reactivity: Vil-A 1 (common ALL-associated antigen) (16), RFA-1 (OKT1, Leu-1 like; thymocytes and circulating T cells) (17), OKT3 (medullary thymocytes and circulating T cells) (18), OKT4 (common and medullary thymocytes, helper/inducer T cells) (19), OKT6 (thymocytes) (19), OKT8 (common and medullary thymocytes, suppressor/cytotoxic $\mathrm{T}$ cells) (19), A10 (OKT10 like; and bone marrow precursors, thymocytes, activated T cells) (20), OKT11 (E-rosette receptor) (19), Leu-9 (thy- mocytes and circulating $T$ cells) (21), OKIa1 (HLA-DR) (22), BA-1 (p30 antigen present on B cells) (3), B1 (B cells) (5).

Vil-Al was generously provided by Dr. W. Knapp (Institute of Immunology, Vienna, Austria). RFA-1 was kindly provided by Prof. G. Janossy (Department of Immunology, The Royal Free Hospital, London, England). A10 was suppled by Dr. F. Malavasi (Istituto di Genetica Medica, Torino, Italy), and OKT11 by Dr. D. Tripodi (Ortho Pharmaceutical Corp., Raritan, NJ). OKT3, OKT4, OKT6, and OKT8 were purchased from Ortho Pharmaceutical Corp. Leu-9 was purchased from Becton-Dickinson \& Co., Sunnyvale, CA, BA-1 from Menarini Diagnostics, Firenze, Italy, and B1 from Coulter Immunology, Hialeah, FL.

In all cases, $1-2 \times 10^{6}$ leukemic cells in a volume of 50-100 $\mu \mathrm{l}$ were incubated at room temperature for $20 \mathrm{~min}$ with the appropriate MoAb. The cells were washed three times with phosphate-buffered saline (PBS) and incubated at room temperature for further $20 \mathrm{~min}$ with a fluorescein conjugated goat anti-mouse Ig (Meloy Laboratories, Springfield, VA). After three more washings with PBS, the cells were scored under a coverslip using a Zeiss Universal Photomicroscope. In all cases, at least 200 cells were analyzed.

Incubation with TPA. TPA (Sigma Chemical Co., St. Louis, MO) was first dissolved in acetone and then in ethanol. Final concentrations of $10^{-9} \mathrm{M}$ were used. In all experiments, $\sim 10 \times 10^{6}$ leukemic cells in $10 \mathrm{ml}$ McCoy's 5A medium supplemented with $10 \%$ fetal calf serum were incubated in flasks for $72 \mathrm{~h}$ at $37^{\circ} \mathrm{C}$ in a humidified incubator in the presence of $5 \% \mathrm{CO}_{2}$ in air. The cells were washed twice, counted, and checked for viability by trypan blue exclusion.

DNA analysis. High molecular weight DNA was extracted from bone marrow or peripheral blood cells of ALL patients separated as described previously. 20-100 $\mu \mathrm{g}$ of DNA were normally recovered from $2-10 \times 10^{6}$ cells. $7 \mu \mathrm{g}$ of DNA from each sample was digested overnight with $30-40 \mathrm{U}$ of Sac I or Eco RI restriction endonuclease. The DNA fragments, size fractionated by electrophoresis in $0.8 \%$ agarose gel, were transferred to nitrocellulose filters according to Southern (23). Filters were hybridized to nick translated ${ }^{32}$ P-DNA probes $\left(1-3 \times 10^{8} \mathrm{dpm} / \mu \mathrm{g} \mathrm{sp}\right.$ act) (24). 4-8 $\mathrm{ng}$ of labelled probe per milliliter of hybridizing solution were used. Hybridization was done in $50 \%$ formamide, $0.9 \mathrm{M} \mathrm{NaCl}, 50 \mathrm{mM} \mathrm{NaH}_{2} \mathrm{PO}_{4}$, and $5 \mathrm{mM} \mathrm{Na}_{2} \mathrm{EDTA}$, pH 7.0, at $42^{\circ} \mathrm{C}$ for $18-24 \mathrm{~h}$, and followed by high stringency washes: twice for $20 \mathrm{~min}$ in $2 \times$ salt-sodium phosphate-EDTA solution (SSPE) ( $1 \times$ SSPE is $0.18 \mathrm{M} \mathrm{NaCl}, 10 \mathrm{mM} \mathrm{NaH}_{2} \mathrm{PO}_{4}$, and $1 \mathrm{mM} \mathrm{Na}_{2}$ EDTA, $\mathrm{pH} \mathrm{7.0)}$ and twice for $40 \mathrm{~min}$ in $0.1 \times$ SSPE, always with $0.1 \%$ SDS, at $60^{\circ} \mathrm{C}$. Hybridization signals were visualized after 3-7 d of autoradiography with intensifying screens.

The probes used were either the recombinant phage Charon $4 \mathrm{~A}$ H24 (25), which carries a 12-kilobases (kb) human DNA fragment inserted by means of Eco RI artificial linkers (Fig. 2, segment a; the Eco RI synthetic sites at the $5^{\prime}$ and $3^{\prime}$ end are not indicated in the map), or subclones of it. A 3.3-kb Eco RI-Hind III fragment, which contain approximately half of the joining $(\mathrm{JH})$ region, was subcloned into pBR322 (pHJ; Fig. 2, segment b, reference 27); a 1.2-kb Eco RI fragment, which contain about two-thirds of the $\mathrm{C} \mu$ gene, was subcloned into $\mathrm{pBR} 325(\mathrm{pH} \mu .30$; Fig. 2 , segment $\mathrm{c})$. The three probes were hybridized subsequently to the same filters carrying DNAs digested with Sac I restriction enzyme.

The choice of this particular restriction enzyme was suggested by the extensive study of the specific hybridization pattern acquired by one of us (N.M.) over a large population sample. 130 unrelated caucasian subjects and $\mathbf{4 0}$ families have been analyzed so far (reference 27 and unpublished data). In all the subjects tested, the JH region 
appeared to migrate with an 11.5-kb fragment, while the $C_{\mu}$ gene within a 4.4-kb Sac I fragment. After long run electrophoresis, the former fragment shows polymorphic variants (11.5-12.0 kb), though such small differences in length are almost undetectable under "normal condition", i.e., $24 \mathrm{~h}$ electrophoresis at $1 \mathrm{volt} / \mathrm{cm}$ and in $0.8 \%$ agarose.

A further advantage of Sac $I$ is that it allows the simultaneous recognition, by means of a $\mu$ switch-containing probe (e.g., fragment a in Fig. 2), of the $\mu, \alpha 1$, and $\alpha 2$ switch regions through the presence of characteristic fragments whose polymorphism and segregation have been described in population and family studies (reference 27; see also legend to Fig. 3). In this respect, it is worthwhile to note that the polymorphism associated to the $\mu$ switch region appeared to derive from the presence or absence of a restriction site in the position indicated in Fig. 2, which accounts for the two major variants of 2.7 and 2.2 plus $0.5 \mathrm{~kb}$. For the other two $\mu$ switch "alleles" described (2.75 and $2.6 \mathrm{~kb}$, respectively, which have a cumulated "gene" frequency of 0.02 ), the molecular basis is not yet known; nevertheless, the chromosomes carrying both such rare variants showed a JH-containing Sac I fragment of the expected germ line length, i.e., $11.5 \mathrm{~kb}$. Thus, the most $5^{\prime}$ located Sac I site within the $\mu$ switch region did not show significant polymorphism so that it could be considered a reliable site for the measurement of the germ line $\mathrm{JH}$-containing segment.

To confirm the Sac I analysis, the same pHJ probe was also employed after Eco RI digestion. In our hands, the germ line Eco RI fragment carrying the $\mathrm{JH}$ region appeared $\sim 4 \mathrm{~kb}$ longer $(\sim 20 \mathrm{~kb})$ than that reported by Korsmeyer et al. (13).

\section{Results}

Immunological findings on primary cells. 19 ALL patients were analyzed. The immunological findings are illustrated in Table I. 16 cases were cALL+, one (case 17) was a non-T,

Table I. Phenotypic Expression and Heavy Chain Gene Rearrangement on Primary and TPA-induced Cells from 19 Cases of ALL

\begin{tabular}{|c|c|c|c|c|c|c|c|c|c|c|c|c|c|c|}
\hline \multirow[b]{2}{*}{ Cases } & & \multicolumn{7}{|c|}{ Primary cells } & \multicolumn{3}{|c|}{ TPA-induced } & \multicolumn{3}{|l|}{ DNA } \\
\hline & & Vil-Al & BA-1 & B1 & Cylg & HLA-DR & A 10 & TdT & BA-1 & B1 & Cylg & $\mathrm{JH}^{*}$ & $\mathbf{S}_{\mu \ddagger}$ & $\mu$ gene§ \\
\hline \multirow[t]{16}{*}{ cALL } & 1 & + & ++ & - & - & ++ & ++ & ++ & ++ & nd & + & s $R / R$ & G/G & G/G \\
\hline & 2 & ++ & ++ & - & - & ++ & ++ & ++ & ++ & - & - & $s \mathrm{R} / \mathrm{R}$ & G/G & $\mathrm{G} / \mathrm{G}$ \\
\hline & 3 & ++ & - & - & + & ++ & ++ & ++ & ++ & + & + & seR/R/R & $\mathrm{G} / \mathrm{G}$ & $G / G$ \\
\hline & 4 & ++ & ++ & - & - & ++ & ++ & ++ & ++ & + & ++ & seR/D & G/D & $\mathrm{G} / ?$ \\
\hline & 5 & ++ & + & - & - & ++ & ++ & -11 & + & nd & + & $s \mathrm{R} / \mathrm{R}$ & $\mathrm{G} / \mathrm{G}$ & G/G \\
\hline & 6 & ++ & ++ & + & - & ++ & ++ & ++ & ++ & ++ & - & seR/R & $\mathrm{G} / \mathrm{G}$ & $G / G$ \\
\hline & 7 & ++ & - & - & - & ++ & + & ++ & + & nd & - & seR/R & G/G & G/G \\
\hline & 8 & ++ & ++ & - & - & ++ & ++ & $-\|$ & ++ & + & - & seR/R & $\mathrm{G} / \mathrm{G}$ & $\mathrm{G} / \mathrm{G}$ \\
\hline & 9ा & ++ & - & - & - & ++ & + & + & - & - & - & $\mathrm{seG} / \mathrm{G}$ & G/G & $\mathrm{G} / \mathrm{G}$ \\
\hline & 10 & ++ & nd & nd & - & + & - & ++ & & & & s R/R & G/G & $G / G$ \\
\hline & 11 & ++ & nd & - & + & ++ & ++ & ++ & & & & $\mathrm{seR} / \mathrm{R} / \mathrm{G}$ & $\mathrm{G} / \mathrm{G}$ & $\mathrm{G} / \mathrm{G}$ \\
\hline & 12 & ++ & $+t$ & - & ++ & ++ & ++ & ++ & & & & $\operatorname{seR} / \mathrm{R} / \mathrm{R}$ & G/G & G/G \\
\hline & 13 & ++ & nd & nd & + & ++ & ++ & + & & & & seR/R & $\mathrm{G} / \mathrm{G}$ & G/G \\
\hline & 14 & ++ & ++ & - & - & ++ & ++ & ++ & & & & $\mathrm{seR} / \mathrm{R} / \mathrm{R}$ & G/G & $\mathrm{G} / \mathrm{G}$ \\
\hline & 15 & ++ & ++ & - & ++ & ++ & ++ & ++ & & & & seR/R/G & $\mathrm{G} / \mathrm{G}$ & $\mathrm{G} / \mathrm{G}$ \\
\hline & 16 & ++ & - & - & - & ++ & ++ & ++ & & & & $\operatorname{seR} / \mathbf{R}$ & $\mathrm{G} / \mathrm{G}$ & G/G \\
\hline \multicolumn{15}{|l|}{ “Null” } \\
\hline $17^{* *}$ & & - & - & - & - & ++ & nd & ++ & - & - & - & seR/R & $\mathrm{G} / \mathrm{G}$ & G/G \\
\hline T-ALL & $18 \neq \ddagger$ & - & - & - & - & - & ++ & ++ & & & & s G/G & G/G & G/G \\
\hline \multicolumn{15}{|l|}{ Undif- } \\
\hline ferentiated $\mathrm{AL}$ & 19 & - & - & - & - & ++ & + & - & & & & $\mathrm{seG} / \mathrm{G}$ & G/G & G/G \\
\hline
\end{tabular}

$+=10-40 \%$ positive cells; $++=>40 \%$ positive cells; and $-=<10 \%$ positive cells. ${ }^{*} \mathrm{G}, \mathrm{R}, \mathrm{D}$ : germ line, rearranged, deleted $\mathrm{JH}-$ containing DNA fragment, respectively. $G / G$ or $R / R$ : both chromosomes in the germ line or in the rearranged configuration. In cases $3,11,12,14$, and 15, three different JH segments were found. The results at the JH "locus" take into account both Sac I(s) and Eco RI(e) Southern blottings. Four cases that, after one-enzyme-test, were judged to be either R/D (three cases) or R/R (one case), after the second enzyme appeared to be $R / R$ (three cases) and $R / R / R$ (one case), respectively. ¥ The integrity at the $\mu$ switch region $(\mathrm{S} \mu$ ) was judged by looking at the "allelic" fragments that were known to map in this region (the 2.7 and $2.2 \mathrm{~kb}$ being the most frequent variants). Sample 4 appeared hemizygous at this "locus". Samples 5, 10, and 12 showed an abnormal intensity ratio between "allelic" bands, which suggested an unbalanced set of chromosomes 14. Indeed, the latter sample showed three different JH segments. § The presence of the 4.4-kb Sac I band, which was obtained either with the switch or the $C_{\mu}$ gene probe (the latter tested in cases $1,2,11$, and 18), gave indication of the integrity of the $\mu$ gene region. In sample 4, it could not be assessed with certainty whether one copy of the $\mu$ gene was included in the deletion of one JH and one $\mu$ switch region. "Tested only in immunofluorescence. T Case 9 was also negative, with RFA-1, OKT3, OKT4, OKT6, OKT8, OKT11, and A10 MoAbs. ** Case 17 was also negative, with E-rosettes and RFA-1, OKT6, OKT11, and Leu-9 MoAbs. ‡‡ Reactive with Leu-9 and RFA-1 MoAbs and negative with OKT3, OKT4, OKT6, OKT8, OKT11 MoAbs, and with E-rosettes. nd, Not determined. 
non-B, non-common ("null") ALL, one was a T ALL (case 18 ), and one was an undifferentiated acute leukemia (AL) (case 19).

Of the 16 cALL cases, all were HLA-DR+, 9/13 were $\mathrm{BA}-1+, 1 / 14$ was $\mathrm{B} 1+$, and $4 / 16$ were $\mathrm{CyIg}+$. The low incidence of $\mathrm{B} 1$ positivity in our series compared to previous reports (5) was a chance finding. In an ongoing multicenter study, the overall frequency of $\mathrm{B} 1+$ cases is $30 \%$ (unpublished data). The non-T, non-B, non-common ("null") ALL was assigned to the lymphoid cell line as it was TdT+ and HLA$\mathrm{DR}+$. The AL case was HLA-DR+, TdT-, and the T ALL displayed an early, pro-thymocytic phenotype reacting with the RFA-1, A10, and Leu-9 MoAbs.

A complete search for B cell-related markers (BA-1, B1, Cylg) was carried out on the primary cells from 13 cases of cALL. Of these, three showed no B cell markers, seven expressed one B cell marker, and three displayed two B cell markers.

TPA stimulation. Cells from 10 patients were stimulated with TPA (Table I). Nine were cALL+ and the tenth was the non-T, non-B, non-common ("null") case. After incubation with TPA, all cases but two were BA-1+; the latter two included the "null" ALL. Two of the eight BA-1+ cases lacked this marker before TPA induction. B1, tested in seven cases, was positive in four; in three of these cases the marker was detected only after TPA stimulation. Cylg were found in four out of the ten TPA-induced cases; three out of four were negative on fresh, unstimulated cells.

All together, after TPA induction, two of the nine cALLs had one B cell related marker (which was not expressed on the primary cells of one case), four displayed two B cell markers (before stimulation 3/4 expressed only one B cell marker), and two had three B cell markers (both cases expressed only one B cell marker before TPA). Only one case (No. 9) remained totally unreactive after TPA. It is important to note that this is the only cALL+ subject who showed no heavy chain gene rearrangement (see below).

Apart from this last case, all cALLs but one (No. 2) increased their B cell marker expression after exposure to TPA (Table I). The non-T, non-B, non-common ("null") ALL (No. 17) remained totally unreactive also after TPA incubation.

Analysis of DNA rearrangements at the heavy chain $I g$ region. In order to detect possible new DNA configurations close to the JH region (Fig. 1), DNA samples of the 19 ALLs studied were hybridized to the pHJ probe (Fig. 2, segment b) after Sac I digestion. All JH-containing fragments that differed in size from the 11.5-12.0-kb germ line length were judged as being due to somatic rearrangement. For a better control of the DNA configuration, the same probe was also tested in combination with a second restriction enzyme: Eco RI.

16 out of 19 samples tested showed new JH organization in at least one copy of chromosome 14 (15 cALLs, 1 "null" ALL) (Table I and Fig. 3). One of the three unrearranged cases was the unique representative of the $T$ cell type ALL

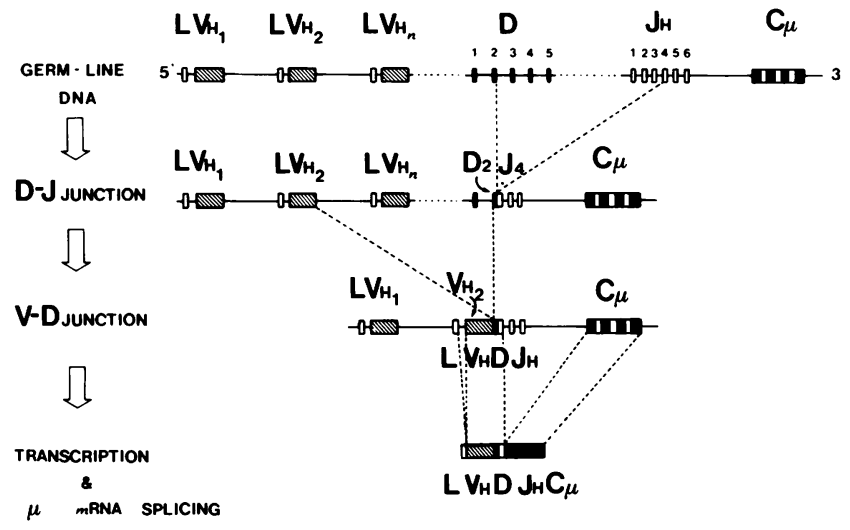

Figure 1. Schematic representation of the DNA rearrangement necessary for the production of a mature $\mu$-mRNA chain. The variable portion of the Ig heavy chain results from the fusion of three noncontiguous DNA segments located on chromosome 14: a variable (VH) gene with its leader (L) segment, a D and a JH element. As shown in the top line, these three segments are clustered in families; multiple VH and D families (only one of the latter is shown) and one single JH cluster are present in the germ line DNA. Therefore, two recombinations, one called D-J, the other V-D, must occur during $B$ cell differentiation. For clarity, the two junctional events have been separated in the figure, although it is not known whether they follow the sequential order that is indicated here (11). The intervening sequencies between the coding elements $\mathrm{L}-\mathrm{V}$ and $\mathrm{J}-\mathrm{C} \mu$ are then removed at the RNA level by splicing. Finally, the mature $\mu$-mRNA is translated into the $\mu$-chain protein.

present in our series (No. 18). The other two unrearranged cases, both of non-T cell origin, were, respectively, a cALL (No. 9) and an undifferentiated AL (No. 19). The only patient classified as non-T, non-B, non-common ("null") ALL showed JH rearrangement in both chromosomes (No. 17).

The pattern of rearrangement observed can be classified as follows: most of the subjects ( 10 cases) had two rearranged JH segments with no germ line counterpart, which indicated that a new DNA configuration had replaced that of the germ line on both chromosomes. A second type of rearranged pattern was characterized by the occurrence of three distinct JH-containing fragments (five cases). Among the latter, two subjects (Nos. 11 and 15) had one of the JH segments in the germ line position, with the other two $\mathrm{JH}$ regions being differently rearranged; the remaining three subjects (Nos. 3, 12 , and 14) had all three different $\mathrm{JH}$-containing segments in a rearranged configuration (Fig. 3). In theory, either a mixture of two cell populations or a hyperploidy could account for the occurrence of more than two JH-containing Sac and Eco RI fragments.

A mixture of a neoplastic and a normal population of cells, though in principle valid only for the two cases with a germ line segment, seemed unlikely, as the proportion of blasts in the latter two cases exceeded $90 \%$, and the intensity of the germ line band was not reduced more than two- or three-fold 


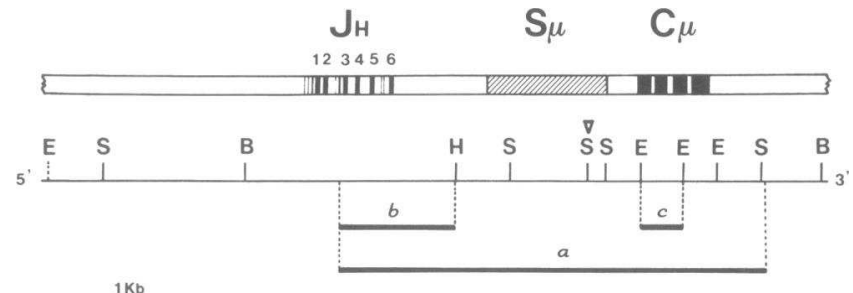

Figure 2. Partial restriction endonuclease cleavage map of the germ line DNA region containing the JH segments (only the functional ones are numbered), the $\mu$ switch region ( $S \mu)$, and the heavy chain $\mu$ gene $(C \mu)$. The map is based on previously published data $(25,26$, 10). However, the extreme $5^{\prime}$ Eco RI site, according to our Southern blottings, should be $\sim 4 \mathrm{~kb}$ farther to the left. Since the Sac I map was obtained by Southern hybridization with probes included in segment a (27), additional Sac I sites might exist beyond the most $5^{\prime}$ and $3^{\prime}$ sites shown. The solid bars below the map represent the probes used in the present work: $a, 12-\mathrm{kb}$ insert in Charon 4A H24 (25); $b, 3.3 \mathrm{~kb}(\mathrm{pHJ})$; and $c, 1.2 \mathrm{~kb}(\mathrm{pH} \mu .30)$. See text for further details. The $5^{\prime}$ and $3^{\prime}$ ends of probe $a$, as well as the $5^{\prime}$ end of probe $b$, are represented by artificial Eco RI sites that were introduced during the construction of the recombinant phase vector. Of the Hind III sites, only one is reported in the figure, in order to show the $3^{\prime}$ end of segment $b$. E, Eco RI; S, Sac I; B, Bam HI; and H, Hind III. $\nabla$, Sac I polymorphic site.

compared to the other two rearranged counterparts (e.g. case No. 15, Fig. 3).

The occurrence of chromosomal hyperploidy in ALs is not rare (28) and could provide an explanation for extra $\mathrm{JH}$ regions. Indeed, karyotype analyses confirmed at least in cases 3 and 14 (the other ALLs with three JH segments gave no scorable mitosis) the presence of hyperploid cells with a frequency of $30 \%$ (No. 3) and $95 \%$ (No. 14). According to these findings, at least one of the additional copies of chromosome 14 should have acquired a novel DNA configuration close to the $\mathrm{JH}$ region after chromosome nondisjunction.

An alternative explanation for the three $\mathrm{JH}$ regions could be an unequal sister chromatid exchange. Since the intensity ratio among the three $\mathrm{JH}$ bands, e.g., in cases 14 and 15 (Fig. 3 ) and in the remaining three cases (not shown), did not appear to differ more than two- or threefold, such an event should have occurred quite early, possibly during the first mitotic divisions after the establishment of the original malignant cell. Nevertheless, the integrity of the $\mu$ switch-containing fragments in all these five subjects (two were heterozygous at the $\mu$ switch "locus", as shown by the presence of 2.2- and 2.7-kb "allelic" fragments), seemed to exclude a crossing over within the major portion of the $\mu$ switch region. If an interchromatid mispairing and crossing over did occur, it appears more likely that it involved the rearranged $\mathrm{V}$ gene on one chromatid and an homologous, unrearranged copy on the sister chromatid.

The last variety of rearrangement found in our series of patients was represented by a case (No. 4) of cALL exhibiting only one copy of the $\mathrm{JH}$ region and this was in a rearranged position. After the analysis with the $\mu$ switch probe it appeared that this case might have deleted a major portion of the $\mu$ switch region in one chromosome. In fact it was apparently homozygote at the $\mu$ switch "locus", but indeed its $\mu$ switchcontaining fragment $(2.7 \mathrm{~kb})$ showed half the expected intensity for a normal homozygote. Therefore, it is highly probable that a broad deletion spanning the $\mathrm{JH}$ and most of the $\mu$ switch region occurred in one chromosome 14.

\section{Discussion}

It is generally thought that B cells acquire the unique property of immunoglobulin production through a multistep differentiation process, of which the most dramatic is the DNA rearrangement at the heavy chain region (8-10) (Fig. 1). This DNA reorganization, which depends upon specific activating events that are still largely unknown, appears to follow a sequential order, occurring first at the heavy chain Ig region, then at the $\kappa$ locus, and eventually at the $\lambda$ region $(12,29$, 30 ). Because of the well established priority of the heavy chain Ig rearrangement, we restricted our study to this DNA region. In fact, either the classical VH-D-JH assembling product or the partial fusion like D-JH can be monitored by the use of a JH probe. In principle, only an isolated VH-D junction could pass unnoticed. In the few cases in which a $D$ region probe was employed (13), a concomitant JH rearrangement appeared. Furthermore, since only some of the $D$ gene families have been cloned, a negative result with a probe from a given $D$ family might not exclude a VH-D rearrangement ahead. Products of incomplete joining involving $\mathrm{D}$ elements have occasionally been reported in murine myelomas; most cases, however, were D-JH joining segments (31) and thus detectable with a JH probe.

The large majority of the ALL patients presented here $(16 / 19)$ had a rearranged JH segment in at least one chromosome (15 cALLs and 1 non-T, non-B, non-common ("null") $A L L$ ). These findings may suggest that the block in differentiation of most ALLs comes after the (VH)-D-JH joining phase, and that the latter occurs at the earliest stages of $B$ cell commitment.

The concept that the (VH)-D-JH assembling process must be one of the first steps towards B cell differentiation is in agreement with our findings regarding a case of "null" ALL (cALL-, HLA-DR +, TdT +, BA-1-) in which both JH regions are rearranged. Korsmeyer et al. (13) observed three ALLs with a "null" phenotype (cALL-, HLA-DR+, BA-1-): all three had one germ line and one rearranged $\mathrm{JH}$ region, while $\kappa$ and $\lambda$ loci were in the germ line configuration. TPA stimulation of our "null" ALL did not induce CyIg, nor other $B$ cell related antigens (i.e., BA-1 and B1), nor the CALL antigen. The uninducibility of the $\mathrm{CALL}$ and the $\mathrm{B} 1$ antigens after exposure to TPA in 5 HLA-DR+, cALL-, B1- patients was also observed by Nadler et al. (7). It appears thus that 


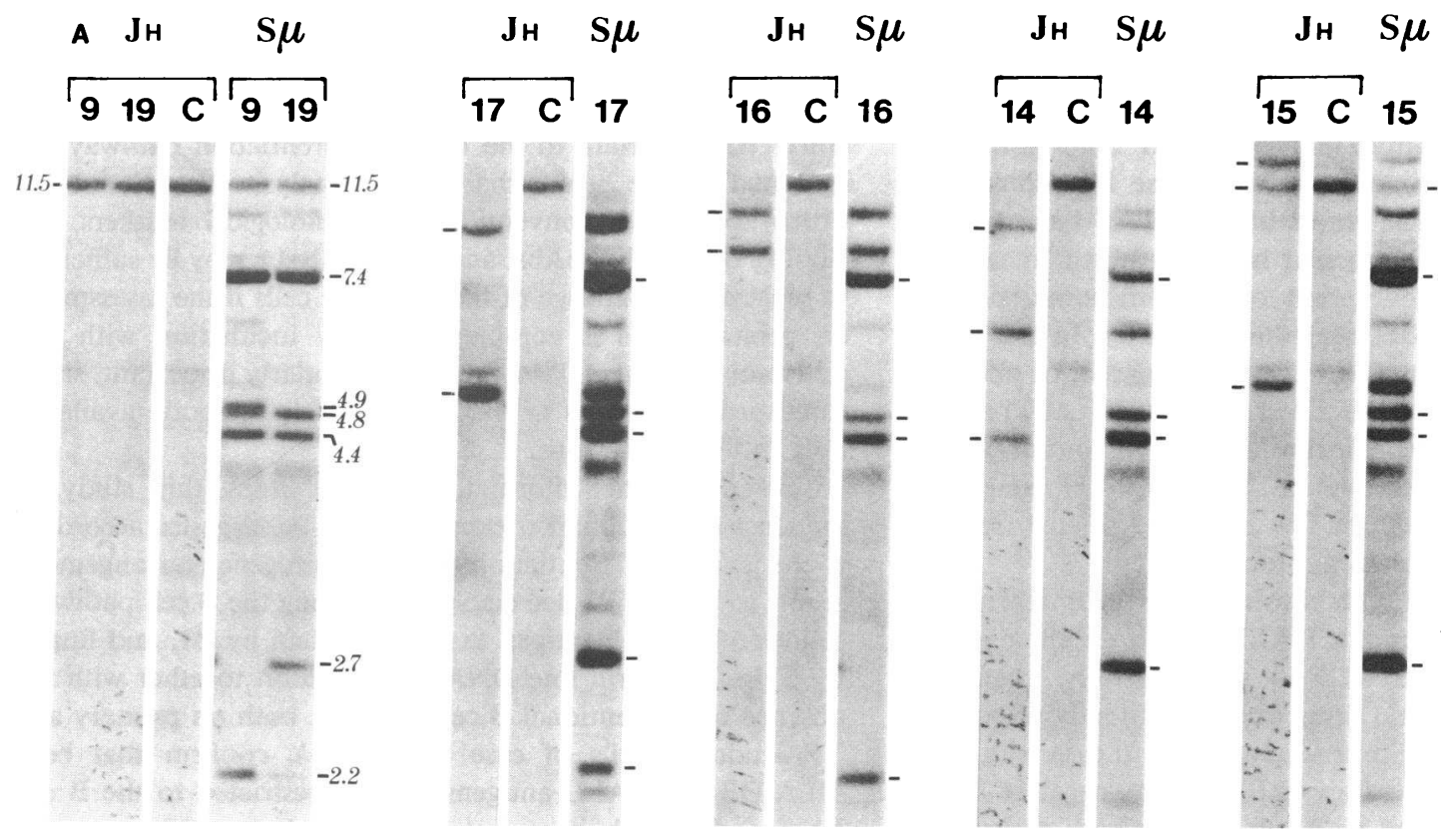

Sac I

B

\section{$J_{H}$}

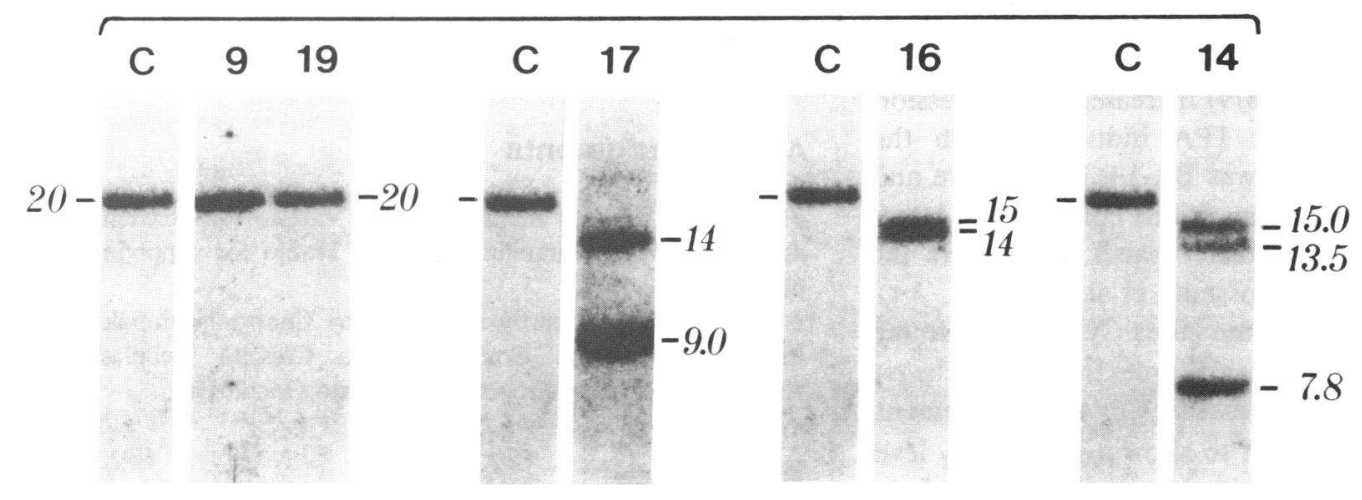

\section{Eco RI}

Figure 3. Southern blotting hybridization of the $\mathrm{JH}$ - and switch region-containing probes (segments $b$ and $a$ of Fig. 2) to Sac I (top, $A$ ) and Eco RI (bottom, B) digested DNAs of six representative cases of ALL. Sac I: the length in kb of the germ line JH-containing segment and of the most relevant $\mu$ switch hybridizing fragments are shown in the unrearranged cases ( 9 and 19). The JH-containing 11.5$\mathrm{kb}$ fragment hybridized to both probes, since it overlapped with the $5^{\prime}$ end of the $\mu$ switch region (see Fig. 1). The 7.4-kb band has been shown to be associated with the $\alpha 1$ switch region; the two fragments of 4.9 and $4.8 \mathrm{~kb}$ represent allelic variants at the $\alpha 2$ switch "locus"; the 2.7- and 2.2-kb bands behave as "alleles" at the $\mu$ switch "locus"; the 4.4-kb band contains the $\mu$ gene (27). C, normal control DNA. The JH probe appeared to share a weak homology also with a $5.5-\mathrm{kb}$ Sac I fragment, which, however, was not rearranged in any of the
ALL cases tested. Eco RI: the germ line length of the JH-containing Eco RI fragment $(\sim 20 \mathrm{~kb})$ is shown in the first three samples (one control and two unrearranged ALLs). In cases 17, 16, and 14, the lengths of the rearranged JH segments are indicated. Case 9 is the unique cALL showing germ line DNA configuration on both chromosomes. Case 19 is an undifferentiated AL (TdT negative) with no evidence of JH rearrangement. Case 17 is a "null" ALL (TdT positive); both chromosomes are rearranged at the JH region. Case 16 is a typical cALL showing heavy chain Ig rearrangement on both chromosomes. Cases 14 and 15 are two cALLs that exhibit three distinct JH segments: in the first, all the fragments are at rearranged positions; in the second, the JH-containing fragments show a germ line configuration. 
other elements, beside the JH rearrangement, are needed in these undifferentiated cases in order to obtain a TPA dependent $B$ cell maturation.

It is worthwhile noting that only two among the 16 rearranged cases still maintain a chromosome 14 with a germ line JH organization. The same likelihood of having both heavy chain Ig regions rearranged has been noted in normal B cells (32), where, however, only one chromosome ends up with a functional VH-D-JH assembling product. In the "nonproductive" chromosome a wide variety of partial or abortive rearrangements have been described which eventually prevent the transcription or full-length translation of an "out-of-phase" message (e.g., when defective or "pseudo" VH genes are trapped in fusion products or few bases are deleted/inserted during the D-J or V-D junction process).

Only three cases with both chromosomes 14 unrearranged at the JH region were found: a T ALL and an undifferentiated AL (TdT-, cALL-, HLA-DR+) unsuccessfully treated at diagnosis with anti-lymhoid drugs and subsequently responsive to anti-myeloid therapy. Surprisingly, the third case with germ line DNA organization was a cALL that was negative for all $T$ cell markers and showed no B cell markers both on primary and on TPA-induced cells. This, to our knowledge, represents the first cALL case with no heavy chain Ig gene rearrangement described.

Using a battery of conventional immunological tests, at least one B cell marker (BA-1, B1, CyIg) was detected, either on primary cells or following stimulation with TPA, in all but one case of cALL. It is important to note that the uninducible case was also the only one among the cALLs that displayed a germ line Ig organization (Table I, No. 9).

The majority of cALL cases (8/9) increased the expression of $B$ cell related markers after TPA induction, with the exception of a case (No. 2) that was BA-1+ both before and after exposure to TPA. These observations confirm in a larger series of patients and with a broader panel of markers the reports of Nadler et al. (7) and Cossman et al. (6).

The demonstration that in some cases Cylg can be found only after TPA stimulation despite the preexistence of a heavy chain gene rearrangement suggests that the DNA rearrangement, although essential, is not sufficient to allow a satisfactory level of heavy chain expression. In this respect, the state of the DNA organization at the light chain loci does not seem to bear any relevance (13). CyIg enhancing factors after VH-D-JH rearrangement appear to be lacking or inhibited in the majority of cALLs. At the present time, the nature of these factors is unknown, except for the fact that in some cases they can be restored or circumvented by exposure to TPA. The evidence that TPA can induce the expression of CyIg suggests that the lack of intracytoplasmic heavy chains on primary cells is probably not due only to ineffective, aberrant gene rearrangement. TPA stimulation is ineffective in non-T, non-B, noncommon ("null") ALLs, as demonstrated by the case reported in our series and by those described by Nadler et al. (7).
However, unlike the latter case, ours appeared to be B-lineage committed, as shown by DNA analysis.

This study indicates that it is conceivable that almost all non-T ALLs pertain to the B cell differentiation pathway, as indicated by the heavy chain DNA analysis. It is, however, worth noting that conventional immunological markers, including BA-1, B1 MoAbs, and Cylg analysis, may be sufficient to suggest the B-lineage of the leukemic cells if the assessment on primary cells is complemented by incubation with the differentiation agent TPA. This is particularly important, since sophisticated analysis at the DNA level is presently available only in few institutions.

Based on the information gained from this study, a sequence of B cell marker expression can be suggested according to the level of differentiation. Heavy chain gene rearrangement seems to be the first detectable event along the B cell pathway, followed by BA-1 antigen expression, then by B1, and finally by Cylg. The germ line DNA configuration together with the absence of conventional B cell markers, both on primary and TPA-induced cells of case 9 (cALL +$)$, confirm that both HLA-DR and cALL antigens are not restricted to the B cell lineage. Although it cannot be excluded that this case may represent the expansion of a B-lineage progenitor before Ig gene rearrangement, with the presently available technologies it could not be assigned either to the $B$ cell (or $T$ cell) differentiation compartment.

In conclusion, the finding that most cases of non-T ALL appear of B cell origin provides a link between ALL and chronic lymphoid leukemias, which have been known for many years to be characterized in the great majority of cases by the monoclonal expansion of neoplastic B cells.

\section{Acknowledgments}

The authors wish to thank Dr. Olga Varetto for excellent technical assistance. We are grateful to Dr. T. Honjo for supplying the H24 phage.

This work was partly supported by Centro Nazionale Ricerche, Progetto Finalizzato Controllo della Crescita Neoplastica grant 83.00818.96, and by Progetto Finalizzato Oncologia.

\section{References}

1. Greaves, M. F., G. Brown, N. T. Rapson, and T. A. Lister. 1975. Antisera to acute lymphoblastic leukemia cells. Clin. Immunol. Immunopathol. 4:67-84.

2. Vogler, L. B., W. B. Crist, D. E. Bockman, E. R. Pearl, A. R. Lawton, and M. D. Cooper. 1978. Pre-B cell leukemia: a new phenotype of childhood lymphoblastic leukemia. N. Engl. J. Med. 298:872-878.

3. LeBien, T. W., J. H. Kersey, S. Nakazawa, K. Minato, and J. Minowada. 1982. Analysis of human leukemia/lymphoma cell lines with monoclonal antibodies BA-1, BA-2 and BA-3. Leuk. Res. 6:299305.

4. Abramson, C. S., J. H. Kersey, and T. W. LeBien. 1981. A monoclonal antibody (BA-1) reactive with cells of human B lymphocyte lineage. J. Immunol. 126:83-88. 
5. Nadler, L. M., J. Ritz, R. Hardy, J. M. Pesando, and S. F. Schlossman. 1981. A unique cell surface antigen identifying lymphoid malignancies of B cell origin. J. Clin. Invest. 67:134-140.

6. Cossman, J., L. M. Neckers, A. Arnold, and S. J. Korsmeyer. 1982. Induction of differentiation in a case of common acute lymphoblastic leukemia. $N$. Engl. J. Med. 307:1251-1254.

7. Nadler, L. M., J. Ritz, M. P. Bates, E. K. Park, K. C. Anderson, S. E. Sallan, and S. F. Schlossman. 1982. Induction of human B cell antigens in non-T cell acute lymphoblastic leukemia. J. Clin. Invest. 70:433-442.

8. Brack, B., M. Hiromi, R. Lenhard-Schuller, and S. Tonegawa. 1978. A complete immunoglobulin gene is created by somatic recombination. Cell. 15:1-14.

9. Ravetch, J. V., U. Siebenlist, S. J. Korsmeyer, T. A. Waldmann, and P. Leder. 1981. The structure of the human immunoglobulin mu locus: characterization of embryonic and rearranged $\mathrm{J}$ and $\mathrm{D}$ genes. Cell. 27:583-591.

10. Siebenlist, U., J. V. Ravetch, S. J. Korsmeyer, T. A. Waldmann, and P. Leder. 1981. Human immunoglobulin D segments encoded in tandem multigenic families. Nature (Lond.). 294:631-635.

11. Sugiyama, H., S. Akira, H. Kikutani, S. Kishimoto, Y. Yamamura, and T. Kishimoto. 1983. Functional $V$ region formation during in vitro culture of a murine immature B precursor cell line. Nature (Lond.). 303:812-815.

12. Korsmeyer, S. J., P. A. Hieter, J. V. Ravetch, D. G. Poplack, T. A. Waldmann, and P. Leder. 1981. Developmental hierarchy of immunoglobulin gene rearrangements in human leukemic pre-B-cells. Proc. Natl. Acad. Sci. USA. 78:7096-7100.

13. Korsmeyer, S. J., A. Arnold, A. Bakhshi, J. V. Ravetch, U. Siebenlist, P. A. Hieter, S. O. Sharrow, T. LeBien, J. H. Kersey, D. G. Poplack, P. Leder, and T. A. Waldmann. 1983. Immunoglobulin gene rearrangement and cell surface antigen expression in acute lymphocytic leukemias of T cell and B cell precursor origins. J. Clin. Invest. 71:301313.

14. Ford, A. M., H. V. Molgaard, M. F. Greaves, and H. J. Gould 1983. Immunoglobulin gene organization and expression in haemopoietic stem cell leukaemia. Embo (Eur. Mol. Biol. Organ.) J. 2:9971001.

15. Bakhshi, A., J. Minowada, A. Arnold, J. Cossman, J. P. Jensen, J. Wang-Peng, T. A. Waldmann, and S. J. Korsmeyer. 1983. Lymphoid blast crises of chronic myelogenous leukemia represent stages in the development of B-cell precursors. N. Engl. J. Med. 309:826-831.

16. Knapp, W., O. Majdic, P. Bettelheim, and K. Liszka. 1982. VIL-A1, a monoclonal antibody reactive with common acute lymphatic leukemia cells. Leuk. Res. 6:137-147.

17. Caligaris-Cappio, F., M. Gobbi, M. Bofill, and G. Janossy. 1982. Infrequent normal $B$ lymphocytes express features of B-chronic lymphocytic leukemia. J. Exp. Med. 155:623-628.

18. Kung, P. C., G. Goldstein, E. L. Reinherz, and S. F. Schlossman. 1979. Monoclonal antibodies defining distinctive human $T$ cell surface antigens. Science (Wash. DC). 206:347-349.
19. Kung, P. C., M. A. Talle, M. De Maria, M. Butler, J. Lifter, and G. Goldstein. 1980. Strategies for generating monoclonal antibodies defining human $\mathrm{T}$ lymphocyte differentiation antigens. Transplant. Proc. 12(Suppl.):141-152.

20. Malavasi, F., F. Caligaris-Cappio, C. Milanese, P. Dellabona, P. Richiardi, and A. O. Carbonara. 1984. Characterization of a murine monoclonal antibody specific for human early lymphohemopoietic cells. Hum. Immunol. 9:9-20.

21. Link, M., R. Warnke, J. Finlay, M. Amylon, R. Miller, J. Dilley, and R. Levy. 1983. A single monoclonal antibody identifies $T$ cell lineage of childhood lymphoid malignancies. Blood. 62:722-728.

22. Reinherz, E. L., P. C. Kung, J. M. Pesando, J. Ritz, G. Goldstein, and S. F. Schlossman. 1979. Ia determinants on human T-cell subsets defined by monoclonal antibody: activation stimuli required for expression. J. Exp. Med. 150:1472-1482.

23. Southern, E. M. 1975. Detection of specific sequences among DNA fragments separated by gel electrophoresis. J. Mol. Biol. 98:503517.

24. Rigby, P. W. J., M. Dieckmann, C. Rhodes, and P. Berg. 1977. Labelling deoxyribonucleic acid to high specific activity in vitro by nick translation with DNA polimerase I. J. Mol. Biol. 113:237-251.

25. Takahashi, N., S. Nakai, and T. Honjo. 1980. Cloning of human immunoglobulin $\mu$ gene and comparison with mouse $\mu$ gene. Nucleic Acid Res. 8:5983-5991.

26. Rabbitts, T. H., A. Forster, and C. P. Milstein. 1981. Human immunoglobulin heavy chain genes: evolutionary comparisons of $\mathrm{C} \mu$, $\mathrm{C} \delta$ and $\mathrm{C} \gamma$ genes and associated switch sequences. Nucleic Acid Res. 9:4509-4524.

27. Migone, N., J. Feder, H. Cann, B. van West, J. Hwang, N. Takahashi, T. Honjo, A. Piazza, and L. L. Cavalli-Sforza. 1983. Multiple DNA fragment polymorphisms associated with immunoglobulin $\mu$ chain switch-like regions in man. Proc. Natl. Acad. Sci. USA. $80: 467-471$.

28. Chaganti, R. S. K. 1983. Significance of chromosome change to hematopoietic neoplasms. Blood. 62:515-524.

29. Hieter, P. A., S. J. Korsmeyer, T. A. Waldmann, and P. Leder. 1981. Human immunoglobulin $\kappa$ light-chain genes are deleted or rearranged in $\lambda$-producing B-cells. Nature (Lond.). 290:368-372.

30. Korsmeyer, S. J., P. A. Hieter, S. O. Sharrow, C. K. Goldman, P. Leder, and T. A. Waldmann. 1982. Normal human B cells display ordered light gene rearrangements and deletions. J. Exp. Med. 156:975985 .

31. Sakano, H., Y. Kurosawa, M. Weigert, and S. Tonegawa. 1981. Identification and nucleotide sequence of a diversity DNA segment (D) of immunoglobulin heavy-chain genes. Nature (Lond.). 290:562565 .

32. Nottenburg, C., and I. L. Weissman. 1981. C $\mu$ gene rearrangement of mouse immunoglobulin genes in normal B cells occurs on both the expressed and nonexpressed chromosomes. Proc. Natl. Acad. Sci. USA. 78:484-488. 